\title{
The Experiences of Work-Life Balance, Stress and Coping Lifestyle of Female Professionals: Insights from a Developing Country Context
}

\begin{abstract}
Purpose:

Given the limiting conditions of gender roles confronting professional working women and drawing on spillover theory, the purpose of this paper is to explore the experiences of worklife balance (WLB) with particular emphasis on the causes of imbalances, perceived stress and coping efforts of female medical doctors from an African context (Nigeria) - a geographical location identified as under-researched in work-life research.
\end{abstract}

\section{Design/methodology/approach:}

The qualitative data is based on one-to-one in-depth interviews with 52 Nigerian female medical doctors.

\section{Findings:}

From the findings of the thematic analysis, it was clear that time squeeze as a well-known factor in the medical profession exacerbates negative work-home interference. However, other themes such as patriarchal proclivities and task-pay disparity affecting female doctors, but rarely considered in work-life studies also emerged as sources of stress and work-family conflicts leaving these doctors to devise individual coping methods as mitigating strategies.

\section{Research limitations and implications:}

The study relies on a limited qualitative sample size which makes generalisation of findings difficult. However, the study contributes to the limited literature on the implications of stress and work-family incompatibilities challenging women in a less egalitarian society with extremely pronounced culture of masculine hegemony contrary to western cultures. The paper unveils socio-cultural difficulties of work-life demands on women specific to the Nigerian society and experienced with a different level of intensity.

\section{Originality/value:}

Majority of work-life research have been undertaken in western countries and have focused on various professional groups and organisations including the health sector. Nevertheless, it is a novel concept within the Nigerian work environment where female medical doctors as a professional group are rarely studied. The paper also provides valuable insights into macrocontextual features influencing WLB of Nigerian professional women.

\section{Introduction}

The Nigerian medical sector is a revered occupation with highly talented workers trained following the introduction of western standards and ethical practices in medicine. However, work in this sector is notoriously intense with growing concerns of medical doctors experiencing job stress associated with the profession (Aslam et al., 2014). Evidence from developed economies such as the UK, Norway and USA, underscore adverse factors such as high job demands and low autonomy as some causes undermining work outputs and WLB of medical professionals (Walsh 2013). Historically, WLB as a social concept is largely 
concerned with inherent demands and struggles encountered in managing work and nonwork-related activities and its propositions often prioritises the experiences of working mothers (Lewis and Humbert, 2010). While significant research has been undertaken on WLB in western countries (Wilkinson et al., 2018) and parts of Asia (Rajadhyaksha, 2012), similar studies remains at nascent stages from an African context. More specifically, little is known from developing countries in Sub-Saharan parts of Africa such as Nigeria with a unique socio-cultural, less egalitarian and collectivistic traditions (Mordi et al., 2013) as opposed to individualistic and economically developed cultures of the west (Hofstede, 1980). Therefore, this paper is a rudimentary effort to fill this gap in response to calls for contextspecific studies focusing on Africa in order to extend knowledge and broaden our understanding of WLB challenges especially in the ubiquitous medical profession (Adisa et al., 2017).

Notable demographic changes since the 1980s lead to the increase of female participation in the labour market arising from desires to seek economic independence, prove self-worth and most importantly, break age-long glass ceiling ideologies that women are not good enough at professional and managerial positions (Agarwal and Lenka, 2015). However, employment relations in most developing countries like Nigeria are organised based on gender norms, creating excessive subordination of women because men are socialised to become breadwinners, while women are always expected to be home carers (Abubakar, 2018). This situation perpetuates a high role overload and caregiving strain, rendering female medical doctors particularly sensitive to work-family issues (Mushfiqur et al., 2018). Focusing on contributing to contemporary debates on women, work, family, stress and coping lifestyle and informed by work-life spillover theory in particular, this study seeks to address from a nonwestern context the following research question: what are the WLB challenges and stress experiences confronting female medical doctors and how do they cope with negative workfamily spillovers?

In addressing this research question, the paper is organised as follows: the next part presents a brief overview of WLB and spillover theory followed by reviews on stress, gender and coping strategies in the literature. Thereafter, the study methodology utilised is explained, along with findings and discussions. The paper ends with conclusions drawn, implications, limitations and areas for future research.

\section{WLB and spillover theory}

WLB has become a somewhat ubiquitous social construct associated with numerous organisational efforts and public policies aimed at enhancing flexible work arrangements, equity and family-friendly outcomes (McDonald et al., 2013). These policies are often aimed at making working adults achieve a balance by gaining "sufficient control and autonomy over where, when and how they work to enable them fulfil their responsibilities both inside and outside paid work" (Visser and Willaims, 2006, p. 14). This 'ideal state' is becoming more difficult as organisations now push for almost round-the-clock working hours (Shockley et al., 2018) which is becoming problematic especially for those with caring responsibilities. Although an adoption of the term 'work-life' as distinct from 'work-family' has gained widespread recognition and paved the way for the universal adoption of a more inclusive terminology. Exponents of work-family studies suggest that WLB has risen from claims of social justice and a need to redress gender discrimination, such as work-family needs of 
women not being treated fairly (Lewis and Humbert, 2010). Given the limiting conditions of gender roles confronting working professional women, it has becomes more difficult to meet care roles satisfactorily. Nowadays, family commitments are a big obstacle to women's career advancement.

While a plethora of research on WLB experiences of professional women in westerndeveloped nations exists in the literature, far less attention has been devoted to similar studies in developing context like Nigeria where the institutional and cultural systems differ from the west. Drawing on spillover theory, this paper seeks explore WLB challenges confronting Nigerian female medical doctors. The study specifically focuses on negative spillover from work to home affairs. Spillover theory state that work and non-work domains are interdependent, and may influence each other either positively or otherwise (Naithani, 2010). Consequently, personal experiences occurring in one domain can be carried into the other (whether work-to-home interference or otherwise). Previous studies (e.g. Du et al., 2018) have shown how individuals cognitively bring finite psychological resources (e.g. mental energy, mood, feelings and emotions) and repeated demands of one's role (e.g. work obligations) drains the availability of these resources and thereby limiting what is left for optimal functioning in other roles.

While depletion of these psychological resources arising from tensions between both domains competing for attention appears universal, the cultural and social context plays an integral role in underlying the nature of work-life imbalances and other elements that give rise to conflict experiences. Evidently, context-specific issues affecting peoples' work-life experiences such as views on societal expectations on gender roles, impact of patriarchy on WLB of female professionals, cultural orientations towards WLB and level of egalitarianism varies from one country to the other. To the best of our knowledge, work-life studies examining these contextual factors are scarce in the literature especially from a context of the black race. This paper is set up to fill a research gap by exploring few of these issues as it specifically affects work to family spillovers, stress and coping experiences of female doctors in a developing country context.

\section{Stress, gender and coping strategies}

Work stress has been widely recognised as one of the main causes of work-family conflict with adverse effects on organisational and employee well-being (Uziel et al., 2018). Stress is generally viewed as adversarial conditions that either taxes or threatens an individual's ability to cope with stressors and eventually results into acute or chronic stress outcomes (Bliese et al., 2017). Acute stresses are short-term stress experiences that occur within a limited period in response to a temporary stimulus while chronic stress is long-term because of the persistent occurrence of stressors (Radenbach et al., 2015). While many stress causes are psycho-social, some scholars argue there is no significant difference in how both genders respond to stress while others hold contrary views (Bonneville-Roussy et al., 2017). In as much as gender may be an essential determinant of predicting stress responses, research has revealed specific situations triggered by workplace sexism increasing higher stress responses from women (Toffoletti and Starr, 2016).

The rising number of women in employment reveal they were more prone to stressors arising from perceived experiences of 'maternal walls' that creates limited career opportunities once they start having children (Thakur et al., 2018). This reality is further exacerbated when 
responsibilities at work interfere negatively with family affairs. Excessive working hours, inflexibility and less positive work environment are factors that can lead to work-family conflict especially in the lives of professional women (Lupu et al., 2018). While significant evidence of WLB challenges among professional women in western countries persists (Poms et al., 2016), similar studies from a Sub-Saharan African context is scarce. Academics have argued that the impact of work stress is higher in developing countries and made worse by a broad range of factors including political instability, social inequality, high illiteracy, inadequate social amenities, poor living conditions and poverty (Chopra, 2009).

Inevitably, the social status of women in developing African countries are subservient to that of men with well-defined domesticated expectations (Cohen, 2006) which inevitable fuels stress as women try to cope with work-family demands. However, prior studies suggest that individual coping dimensions can mediate the relationship between intense work obligations and family roles (Higgins et al., 2010). Hernst et al., (2007, p. 12) defined coping as 'an effort to create conditions that permit an individual to continue moving towards desired goals [...] coping is a response which follows a stressful experience'. In theory, Lazarus and Folkman (1984) portrayed coping as psychological and behavioural efforts utilised to mitigate demanding situations appraised as taxing and exceeding an individual's resources (e.g. time and energy) and proposed a model of two coping dimensions categorised as (i) problemfocused coping - viewed as adopting proactive measures to reduce, alter or remove stressors and (ii) emotion-focused coping proposed as either showing signs of psychological endurance or tolerance of stressful encounters. While work-life conflict has been identified as a universal social problem in the literature, empirical research examining contextual coping methods used particularly by Nigerian working mothers in dealing with this social problem are relatively few (Adisa et al., 2016). More so, it is perceived that a dearth of literature exists on this issue among African career women leaving their experiences under-theorised. Hence, this study also aims to extend knowledge in this regard.

\section{The study context and WLB of doctors}

Nigeria has a population of about 190 million people spread across over 250 ethnic groups (National Population Commission of Nigeria, 2017) while one of the most prominent whitecollar job in the country is the medical profession. The Nigerian healthcare sector comprising of the private, public and government hospitals, have responsibility for providing healthcare services and its affairs are regulated by the Medical and Dental Council of Nigeria (MDCN). Health care provision in Nigeria are divided into categories namely; (i) primary health care (which is basic care for all and health care providers have little or no years of experience in health care provision except for the years spent in this setting), (ii) secondary health care (where medical practitioners provide specialist care to patients and are made up of those with advanced academic degrees and also a mixture of those with experience in primary health care delivery) and (iii) tertiary health care (responsible for the provision of more specialized or consultative services to patients and medical personnel here are people with both advanced degrees and many years of medical experience)(Auta et al., 2016).

Records reveal Nigeria has the largest number of health workers in Africa, with increasing numbers of qualified doctors (Adisa et al., 2017). However, the underrepresentation of female doctors in Nigeria is evident (Makama et al., 2012). The dominant reason for this is that the Nigerian medical work environment is underpinned and governed by patriarchal management 
values. As at 2014, for instance, a total of 28,139 doctors and 1,375 dental surgeons were issued with practising licences, which constitutes the current total stock of 29, 514 medical practitioners in Nigeria, but overall, females constituted only $33 \%$ of all licensed practitioners (Adisa et al., 2014). This shows fewer number of females train as doctors based on strong existence of masculine hegemony shaping the Nigerian culture.

In a study revealing how female doctors are marginalised in the profession, Ekop's (2019) study found that Nigerian female doctors rarely occupy senior leadership and privileged positions in the medical practice (e.g. Medical Directors, Chairman of Medical Advisory Committees, President of Medical Associations) because of the stiff opposition women encounter from higher numbers of male colleagues vying for the same positions and cultural norms that primarily saddles women with home care responsibilities. When this is added to the long hours spent in the hospital, it can be quite challenging and making WLB difficult for female doctors. Although WLB to female doctors are important but the uncompromising requirement of physical presence at hospitals and working in pressured environments leaves them vulnerable to stress and work-family conflicts. These conditions are further exacerbated by the increasing report of chronic shortage of health personnel, with a doctor-patient ratio of 500 doctors to one million Nigerians (Adisa et al., 2016).

Generally, the working conditions of Nigerian doctors are not encouraging. Inadequate public funding of primary health care, doctors' brain drain, poor remuneration, impoverished medical facilities, prolonged industrial strikes by doctors and corruption are some of the disturbing realities plaguing the country's health sector (Adisa et al., 2014). These concerns are compelling massive migration of doctors to greener pastures (i.e. developed countries). According to Hagopian et al., (2004) migration of Sub-Saharan African doctors to the United States revealed how nearly $86 \%$ of African physicians practising in the US originates from mainly three countries - South Africa, Ghana and Nigeria. Female doctors are part of this large number of migrants to foreign countries that offers them better remuneration and friendly-family policies.

\section{Research methodology}

This study is guided by interpretive constructionism which gives researchers an opportunity to discover rich narratives from lived experiences (Saunders et al., 2012). Thus, a qualitative design was considered appropriate for this study and the rationale for the approach is motivated by an interest to get in-depth understanding of the researched phenomenon (Creswell, 2013). Furthermore, the paucity of extant research on women, stress, WLB and coping issues from a Sub-Saharan African context may suggest empirical testing with preconceived hypothesis may be pre-mature and inadequate to explore intricate taken-forgranted assumptions of lived experiences (Akanji et al., 2019). The key informants of the study were drawn from federal (i.e. public), and private hospitals in four major city-states in Nigeria. Snowballing as a non-probability sampling method was used as a primary source of data collection which entailed existing subjects providing referrals to recruit samples required for the study (Ekman, 2015). The eligibility criteria were as follows: First, the participants must be registered with MDCN that is the regulatory body of medical practice in Nigeria. This information was confirmed from their respective hospitals. Second, they are required to have considerable level of medical work experience (i.e. practicing for 3 years and above). Third, all participants selected for the study had children irrespective of marital status (i.e. 
single mothers, married or divorced). In order to fulfil our promise of confidentiality, pseudonyms were used to represent the interviewees who were labelled (Doctor 1-52) for the purpose of our study.

Participants completed consent forms and were informed of rights to voluntarily withdraw from the study at any stage in the interview. Four doctors who were the only ones below 35 years subsequently withdrew for personal reasons. In total, 52 female doctors ranging for ages (35-55) showed keen interest to participate. They comprised of general practitioners and consultants in various specialist fields of medicine such as clinical surgery, paediatrics, dermatology, neurology, gynaecology and general practice. The individual semi-structured interviews lasted for about 40-60mins and were conducted on-site. Data collection lasted for four months. In terms of assessing the reliability of the study, the researchers met frequently for debriefs to compare interview notes and ensure all interview protocols were completely covered so that data collected is defensible (Lincoln and Guba, 1985). Open ended questions were asked which allowed for flexibility during interactions. Participants were initially asked the same core questions at different times and locations in order to check for alternative explanations in reducing chances of biases (Creswell, 2013). Representative of the questions asked are:

1. What constrains your work-life balance as a female doctor?

2. What factors makes your work life encroach into your family life?

3. Describe how you cope with experiences of work-family conflict?

All the interviews were audio-recorded and helped in identifying what might be missed during each sessions so that supplementary interviews could be conducted to seek clarifications where relevant. After conducting 45 individual interviews, the researchers perceived that emerging themes were recurrent and it became unlikely that further data collection would yield new themes. To ascertain that saturation point has been reached (Guest et al., 2006), a further seven confirmatory interviews were conducted. However, the additional interviews merely corroborated the existing themes emerging from previous ones.

\section{Data analysis}

The analysis began by transcribing all interviews. After transcription, the researchers once again went back to each recordings and gleaned through every word to make sure the transcribed accounts exactly matches the recorded version. Upon completion, we meticulously used the coding system which is a well-established method in qualitative research. This is an analytical process through which data are fractured and integrated to form conceptual themes grounded in the data. In doing this, we started with the first cycle of coding which involved assigning a word or short phrases that symbolically describes attributes of the informants' views from transcribed data addressing our research inquiry (see Table 1 below).

\section{Insert Table 1 here}

For purposes of enhancing 'dependability' (in preference to reliability) often used in quantitative research (Lincoln and Guba, 1985), each researcher coded independently but afterwards came together for peer scrutiny which has been identified as a good way of judging a good qualitative reporting. At the second stage of codifying (Saldana, 2012), codes with similar characteristics (underlying meanings and ideas) were identified and 
appropriately collapsed to create conceptual categories (see Table 1). This made the firstorder coding 'more theoretical and more abstract' (Pratt et al, 2006, p. 240). Finally, the conceptual categories were merged in a bid to generate theoretical explanations for the occurrence of the phenomenon understudy (see Table 1). In ensuring credibility of the qualitative inquiry, the inter-rater reliability was checked by inviting two experienced qualitative experts to randomly review our coding and categorisation scheme independently. Their inter-rater reliability result was around $89 \%$ showing a high level of agreement which is well above the minimal threshold (kappa 0.70) suggested by Cohen (1960).

\section{Findings and discussions}

In response to the main research question, this section analyses and discusses main themes emerging from the study data.

\section{Time squeeze}

From our findings, the sources of work-family conflict are working long hours and acceleration of the pace of daily work life which leaves less time to spend on home affairs. $55 \%$ of the doctors reported working long (e.g. 90-92 hours per week) and unsociable hours coupled with intensive work pressures which makes them fatigued to respond to family matters. Interviewees explained that the thriving long hours' culture of the medical profession, lack of legislative and institutional framework regulating working time, shortage of doctors, poor medical and social amenities were contextual factors exacerbating negative spillovers from work to family domain. The following quotations typify shared views:

My WLB concern is the long hours I work (90 hours per week) due to inadequate number of doctors at my hospital. I'm sometimes here on weekends and public holidays [...] After my night shifts, I get stuck in the 6am morning rush-hour Lagos traffic congestion with horns blaring, driving on bad roads and inhaling exhaust fumes from cars causing health hazards [...] I usually get home worn-out and struggle to spend five minutes with my kids before bedtime $[\ldots]$ it lowers my desire to go to work the next day (Doctor 10).

...I work 92 hours per week. It sometimes affect my health. Engaging in extended working hours is obviously an ancient culture of the medical profession. The amount of hours we spend as doctors in this part of the world is stressful and damaging our family lives as mothers [...] I really wish the Nigerian government can pay attention to sustainable work systems whereby working time is regulated so that working mothers can at least create some level of work-family balance (Doctor 11).

The poor state of medical facilities in Nigeria coupled with a lack of an enabling environment for us who are saddled with family responsibilities are factors making me strained to perform my role as a wife and mother (Doctor 12).

Two of the participants specifically spoke of how the long working hours and pressures of medical practice is threatening their marriages.

My husband feels my prolonged stay at work since my appointment as the head of all surgeons in my hospital is adversely affecting the quality of time spent at home and he feels it is straining our union because we don't even have time together (Doctor 13).

I'm always pressed for time as a senior consultant which is encroaching into my family and religious life [...] my husband is really worried for our children and marriage sometimes (Doctor 14). 
The preceding excerpts illustrates context-specific factors making it difficult for female doctors to maintain a balance between work and home management. In this respect, negative work-to-home interference is experienced from the volatile contextual issues of medical practice in Nigeria (culture of working long hours, shortage of doctors, poor medical facilities etc) and found to adversely impact on daily family affairs. These factors have brought about a dramatic shift in the allocation of time and energy devoted to paid employment at the expense of unpaid caregiving responsibilities.

Conceptually, the findings reveal time and strain-based conflict outcomes occurring as a result of work-to-family conflict spillovers. Evidence of time-based conflict for instance, makes it difficult to fulfil demands at home while strain-based conflicts are experienced when fatigue and stress emerging from working hard and long affects familial duties (Sok et al., 2014). These findings further confirms the extent to which negative spillovers have profound implications for backlash attitudes that are potentially counterproductive to work performance (Beauregard, 2014). This was evident through expressions of lower morale (e.g. 'it lowers my desire to go to work the next day') and impairs physical wellbeing ('I work 92 hours per week. It sometimes affect my health') and increases greater feelings of strain arising from time squeeze experiences.

\section{Patriarchal proclivities}

Perspectives shared by $25 \%$ of participants' revealed patriarchy as a traditional and institutionalised system that underrates the social conditions of women's WLB in Nigeria (Adisa and Isiaka, 2019). Findings indicates women as playing dual roles as income earners to support the family purse as well as home carers while men are portrayed as the absolute head of the home. Based on this societal perception and internalised assumptions of masculine supremacy, concerns were raised about the lack of spousal support in helping with family care which exacerbates WLB difficulties and stress. These views were illustrated as follows:

Most times I'm stressed as a doctor after an extremely demanding day at work [...] my husband sometimes feels my profession is overbearing because I don't get to cook his meals and look after our children which is expected to be the first responsibility of a women in our society (Doctor 15).

One exasperating experience for me is our societal ideology that women, regardless of their status and profession even if it means working from home, are responsible for household chores, bearing and raising children while our men (husbands) hold authority over us [...] I rarely have an ideal WLB because my call times as a doctor puts me in the hospital longer, making it difficult and stressful to meet mandatory home functions (Doctor 16).

...I bring work home to complete before the next day which interrupts me sometimes at home. I also meet stiff opposition from my husband who believes that I should always focus on family matters at home and not office work [...] this male domineering attitude is disturbing (Doctor 17).

These findings confirm evidences from prior studies (e.g. Makinde et al., 2017; Adisa et al., 2019) that have revealed the extent to which patriarchy undervalues WLB of professional women and increases chronic stress conditions. Although many work-life studies have focused on the effects of negative work-home spillovers, less is known about its contextual antecedents from developing countries. Nevertheless, some relevant information is made 
available in this study. Thus, Adisa et al., (2019, p. 25) reveals patriarchal tradition is always targeted at consigning "women's WLB to the mercy of their husbands, partners or fathers" while men are always justified as having absolute authority over women and their professional life.

Drawing on the spillover theory, the interruptive concerns of bringing extra office work home (i.e. '...I bring work home to complete before the next day which interrupts me sometimes at home ...') as well as patriarchal norms shaping gender roles unveils the lack of social sustainable work-life practices confronting female doctors in the Nigerian environment. Moreover, this historically rooted and psychologically internalised state of patriarchy negatively affects the ability of professional women to support their family as dual earners. This form of societal prejudice is said to be a severe phenomenon in all kinds of research and human activity (Dick and Nadin, 2006). Such cultures are ingrained in parts of South Asia and Africa than economically developed western countries.

\section{Task-pay disparity}

Ten of the participants were more emphatic about how stress impairs their ability to provide good secondary and tertiary patient care arising from the tedious efforts they put into work which is not commensurate to received rewards. Insights from the interviews uncovered disparity between physician-perceived quality of care service rendered to patients and reward systems.

My stress problems arises from my overwhelming workload demands that is disproportionate to my salary and allowances [...] this puts financial stress on me because my pay is not sometimes enough to cater for all my expenses at home since my divorce (Doctor 18).

The constraining factor is that I work so hard seven days at a stretch and expected to assess 20-30 patients on admission per night [...]. Sometimes about the fifth night, I'm maybe missing little but essential things in the results or not spotting things clearly in x-rays because I maybe drowsy due to exhaustion which beclouds my judgement but our take home pay is so discouraging and sad. My husband and I hit rock-bottom after meeting our financial obligations to our children and extended families (Doctor 19).

The foregoing comments, in addition to those in Table 1, portrays negative spillovers built up at work (i.e. high occupational demands and low reward system) and transferred to the home front as reasons for financial difficulties and inability to adequately support family demands. This process is well understood from Siegrist's (1996) effort-reward imbalance model that focuses on social reciprocity effects and how psychosocial stress occurs in individuals as a result of sustained unfair trade-off between efforts and rewards. Therefore, expressions such as ('puts financial stress on me' and 'our take home pay is so discouraging and sad') elicits a process which might result in a spillover of stress into home affairs arising from disparities between energy exerted at work and perceived low reward for labour. Given the realities that working female doctors experience stress and negative work-home interference specific to the Nigerian environment and medical practice, further enquiries explored types of coping styles adopted to deal with work-family difficulties.

\section{Coping strategies}

$50 \%$ of participants mentioned getting support from extended family members and parents to help with childcare. Thus, family-kin dependence is well pronounced in Nigeria unlike 
developed countries like the UK where paid au pairs are often used since family members are rarely available to help (Adisa et al., 2016). The following comments elaborate on these type of support system:

I am able to reduce my negative work-family interference by getting two on my husband's nephews to live and look after our children (5 and 7 years old) while we are away working long hours $[\ldots]$ it is a good that we can always have family members to help which is part of our culture (Doctor 20).

My mother lives with us and supports me with childcare while I sort out of her health issues as a doctor since it is mandatory we take care elders in our society (Doctor 21).

The family system support helps relieve conflicting spillovers and an important coping strategy based on our findings (see also Table 1). In this context, a major social fabric of Nigeria is its collectivistic system where individuals develop strongly knitted social ties and strong sense of obligation to support one another (Mordi et al., 2013). It is evident that Nigerian working mothers rely on families as a problem-focused coping style (Lazarus and Folkman, 1984) despite the informal nature of this support system. It also emerged as common practice in Nigeria to employ the services of house helps for general household labour and childcare. For instance, 29\% of participants preferred domestic keepers (popularly referred to as 'house-help' in the Nigerian society).

In coping with my immediate care responsibilities, I have two house helps from my village. They are poor but always willing to work for cheap money [...] my only concern is that my 'helps' don't have basic education because their parents can't afford it and I sometimes feel tensed leaving my children with them but I have no choice. So I send them to school to make them more useful to me (Doctor 22).

Typically, in the Nigerian society, house helps, particularly young females are recruited from poor rural communities where their parents lack basic sources of livelihood to cater for their children but would rather send them out to serve as casual domestic workers in urban cities (Akanji, 2013). However, there are expressed concerns about this cheap labour (see Table 1). From the preceding quote, the fact that these house helps are poorly skilled, uneducated and lack childcare experience seriously questions the effectiveness of these coping method (e.g. 'I hired a female house girl to take care of my children. She is an illiterate but I have no option for now'). Rotondo et al., (2003, p. 277) argues that "in the domain of coping effort, effort is not synonymous with productive effort". This is because the beneficial impact of a coping strategy in moderating work-life conflict and negative spillovers occurs via appraisal of such methods. From this perspective, the behavioural manifestation of seeking social support from paid housekeepers puts in doubt the efficacy of the coping style drawing on the narrative of Doctor 22.

Furthermore, six participants in particular, shared how their coping lifestyles are cognitively built around sharing their work-family concerns with other female work colleagues who can relate to how achieving WLB can be extremely difficult for Nigerian mothers (see Table 1). This is further exemplified in the following cluster:

I have a few of friends at work whom we share concerns about the daily hassles we face in combining our medical practice with family life. We share our common coping challenges $[\ldots]$ it is so gratifying to hear the experiences of other colleagues and mothers $[\ldots]$ it gives me inner strength to endure... (Doctor 23). 
What I do is seek advice and comfort from my fellow female doctors on how to cope with pressures making my work and home affairs incompatible. I think staying positive after confiding in my doctor friends gives me emotional stability to fight on despite all odds (Doctor 24).

The samples above suggests managing experiences associated with stress and WLB challenges occurring via cognitive dimensions (Larazus and Folkman, 1984). This emotionfocused coping in the form of positive thinking or finding solace in sharing work-family concerns may likely predispose these doctors to viewing the intrusive nature of their work into family life as less than hopeless and remediable. Thus, cultivating friendships was revealed as a coping strategy. The importance of building meaningful friendships is beginning to emerge in WLB literature as being salient for well-being and social integration, especially in the provision of social support networks for today's workers battling to maintain an overall sense of work-family harmony (Pedersen and Lewis, 2012). Friendships can signify worthy informal ties between people who are happy to form close bonds and support each other's work-life issues. However, this may be far less a proactive solution when compared to direct actions such as help-seeking measures earlier examined. More so, friendships are adjudged to be highly context-dependent and change across the life-course of an individual (Pedersen and Lewis, 2012). Therefore, reliance on friendships based solely on the homogeneity of a workgroup may only be instrumental in this particular context.

\section{Conclusion and implications of study}

\section{Research and theoretical implications}

This study provides insights into WLB challenges, stress experiences and coping strategies within the context of Nigeria with a focus on female medical doctors. In this paper, we aimed an under-represented region and showed the importance of context when addressing stressors and negative work-home interference affecting professional women in a less egalitarian culture. Situated in a national context (Nigeria) that has been neglected in favour of western based research, the results of our research evidence captures contextual themes distorting WLB of Nigerian female doctors. Thus, our study has made important research and theoretical implications.

In terms of contributions to work-life research, our findings show participants' perception of feeling rushed, stressed, or otherwise crunched for time arising from pressurised job demands and long working hours of the medical culture which in turn exacerbates stress from failing to effectively engage with family commitments. In addition, our data points to other wider contextual factors (e.g. shortage of doctors, poor medical facilities, bad roads and patriarchy) highlighted as key triggers of negative work-family interference. The effects of these macro context-specifics (e.g. patriarchal proclivities and task-pay disparity) challenging WLB of professional women are rarely considered in the literature. We argue that significant evidence of western work-life studies appear to historically oversimplify issues on how to micro manage WLB dilemmas especially of affluent professionals and white collar workers by predominantly focusing on scrutinising organisational flexibility in working arrangements, the need for more family-friendly policies and the need to endorse non-standard work in order to cater, in particular, for those with family obligations (Feeney and Stritch, 2017). While these relevant debates are increasing the popularity of WLB discourse and legitimises widely felt importance to avert paid work from invading into the private lives of working 
mothers, our study further validates the need to address WLB concerns from wider messages and broader cultural inclinations of a different context other than Anglo-Saxon societies (Lewis et al., 2007).

More so, Özbilgin et al., (2010) argues that it is unknown if such western-based findings are valid in less comparable settings. As observed for instance, Chandra (2012, p. 1040) found that 'in Asian countries gender socialization played a major role in one's perception towards WLB, and coping strategies were also individual driven while American multinationals focused on flexible working practices'. As such, our findings impliedly validates Chandra's cross-cultural views by revealing concerns of Nigerian professional mothers where strong patriarchal values, male chauvinism and a history of perceiving women as 'housewives' is greater than the west where it is a norm based on strict adherence to workplace equality and diversity policies for 'women across the social spectrum to be employed' (Lewis et al., 2007). More worrisome is the effort-reward disparity that imposes financial family pressures on female doctors. It has been found that this may be a contributory factor for medical errors arising from de-motivation to work efficiently arising from low pay which has profound implications for other 'backlash' attitudes and behaviours (i.e. negative reactions that are potentially counterproductive to organisational performance) (Beauregard, 2014) evident from our findings.

Furthermore, our data foregrounds how participants adopts a range of coping strategies, as touched upon earlier (see also Table 1). For majority of the participants, outsourcing their childcare responsibilities to housekeepers (mostly unqualified maids) and drawing on family networks for support appears commonly used to reduce work-family conflict to some certain extent. This evidence resonates with Adisa et al., (2016)'s study, whose findings reveal that based on the social restrictions placed on Nigerian women coupled with the lack of social policy and HR interventions to assist women's coping needs, results in the daily struggles they face in combining parenthood with career goals and only indulge in few traditional coping methods which fails to adequately address their plight. In addition, our findings revealed a small number of participants engaging in personal coping of sharing work-family problems with colleagues and eliciting emotional comfort from the process. However, this coping strategy is still no substitute for institutionalised social care systems such as registered childcare centres, childcare leave benefits, crèche facilities, nanny share, flexible work arrangements, au pairs and standard statutory maternity leave available to working mothers in developed western economies such as Britain (Smith et al., 2011).

On theoretical implications, our findings highlights, through the lens of spillover theory, how socio-cultural nuances are precursors for understanding reasons behind negative spillover experiences occurring from work to home in a different national context. Therefore, we argue that popular calls for universal adoption of WLB discourse that focuses on 'gender neutrality, individual choice and cultural neutrality' (Lewis et al., 2007) may undermine taken-forgranted assumptions upon which it is originally based (i.e. women and work-family conflicts). Needless to say, women in various countries experience negative work-family interference differently and contextual factors prompting attention to these challenges vary and sometimes beyond the control of women in these societies (e.g. patriarchy in Nigeria). While working mothers in Nigeria rely on some degree of problem-focused and emotionalbased coping strategies of their own, problem-focused coping (i.e. direct action) is found as more efficacious in managing work-related stressors than emotion-based coping (Cash and 
Gardiner, 2011). For instance, family role-redefinition (e.g. help seeking strategy) is found to moderate the relationship between negative work-family spillovers and stress (Rotondo et al., 2003).

\section{Practical implications}

Given the insights gleaned from our study findings, institutional and attitudinal changes on the part of the hospital management in Nigeria has become needful for a possible realisation of positive HR outcomes and sustainability gains (Mushfuqur et al., 2018). More specifically, strong legislative emphasis should be placed on introducing a Nigerian working time law that would regulate working hours similar to those of European countries. For instance, doctors in developed economies like the UK have rights to fair working conditions as set out the Working Time Directive (2003) in the European Union law. In protecting doctors from working long hours, the directive reduces the working week to an average of 48 hours and further regulates break periods and holiday allowances. This can help ameliorate work-family challenges of female medical doctors and create social sustainable work outcomes. Additionally, it has become apparent for feminist citizenship discourse and advocates of gender equality in the Nigerian medical sector to focus on the need to incorporate 'ethics of care and social justice' agendas for working mothers (Lister, 2003). HR practitioners and hospital managers in the Nigerian medical profession should be trained on the importance of implementing flexible work options as a primary source of stress management intervention. These organisational training agendas will have a huge implication for sustainable and 'green' WLB for female doctors (Adisa et al., 2014).

\section{Study limitations, and areas for future research}

Despite the study making important contributions to the field by examining stress and WLB struggles and coping strategies of Nigerian female doctors, some study limitations are identified that should be addressed in future research. First, this study is limited to female doctors. These is a highly respected and demanding white-collar jobs in Nigeria and future studies might consider whether different WLB concerns arise from other occupational groups including manufacturing, sales, or casual employments. Secondly, future research should examine accounts from male doctors for purposes of reporting balanced views of WLB challenges emanating from masculine perspectives. Third, the study adopted an interpretive constructionist methodology which makes our study exploratory in nature (Saunders et al., 2012). In a sense, the purely qualitative design adopted may make findings only tentative because of the small sample size used. Future quantitative research involving hypothesis testing with larger sample sizes is imperative for generalisation of findings. Finally, it would be interesting to engage in cross-cultural research that compares the Nigerian context with western cultures.

\section{References}

Abubakar, M. (2018), "Linking work-family interference, workplace incivility, gender and psychological distress", Journal of Management Development, Vol. 37 Iss: 3, pp. 226-242.

Adisa, T. A. and Isaika, S. B. (2019), "Patriarchal hegemony: Investigating the impact of patriarchy on women's work-life balance", Gender in Management: An International Journal, Vol. 34 Iss: 1, pp. 19-33. 
Adisa, T. A., Gbadamosi, G. and Osabutey, E. L. C. (2016), "Work-family balance: A case analysis of coping strategies adopted by Nigerian and British mothers", Gender in Management: An International Journal, Vol. 31 Iss: 7, pp. 414-433.

Adisa, T. A., Mordi, C. and Mordi, T. (2014), "The challenges and realities of work-family balance among Nigerian female doctors and nurses", Economic Insights - Trends and Challenges, Vol. 3 No. 3, pp. 23-37.

Adisa, T., Mordi, C., and Osabutey, E. (2017), "Exploring the implications of the influence of organisational culture on work-life balance practices: Evidence from Nigerian medical doctors", Personnel Review, Vol. 46 Iss: 3, pp. 454-473.

Akanji, B. (2013), “An exploratory study of work-life balance in Nigeria: Employees' perspectives of coping with the role conflicts", International Journal of Research Studies in Management, Vol. 2 No. 2, pp. 89-100.

Akanji, B., Mordi, C., Ituma, A., Adisa, T. and Ajonbadi, H. (2019), "The influence of organisational culture on leadership style in higher education institutions", Personnel Review, DOI/10.1108/PR-08-2018-0280 (in press).

Aslam, H. D., Jamil, R. and Tariq A. (2014), "Stress in medical practitioners in private healthcare industry", Asian Sociological Science, Vol. 10, pp. 11-16.

Bliese, P. D., Edwards, J. R. and Sonnentag, S. (2017), "Stress and well-being at work: A century of empirical trends reflecting", Journal of Applied Psychology, Vol. 102, No. 3, pp. 389-402.

Bonneville-Roussy, A., Evans, P., Verner-Filion, J. and Vallerand, R. J. (2017), "Motivation and coping with the stress of assessment: Gender differences in outcomes for university students", Contemporary Educational Psychology, Vol. 48, pp. 28-42.

Cash, M. L. and Gardiner, D. (2011), "Cognitive hardiness, appraisal and coping: Comparing two transactional models", Journal of Managerial Psychology, Vol. 26 No. 8, pp. 646-664.

Chandra, V. (2012), "Work-life balance: Eastern and western perspectives", The International Journal of Human Resource Management, Vol. 23 Iss: 5, pp. 1040-1056.

Chopra, P. (2009), "Mental health and the workplace: Issues for developing countries. International Journal of Mental Health Systems", Vol. 3 No. 4, pp. 1-9.

Cohen J. A. (1960), "Coefficient of agreement for nominal scales", Educational and Psychological Measurement Vol. 6, pp.37-46.

Cohen, M. F. (2006), "The condition of women in developing and developed countries. The Independent Review", Vol. 11 No. 2, pp. 261-274.

Creswell, J. W. (2013). Research design: Qualitative, quantitative, and mixed methods approaches. Sage publications.

Du, D., Derks, D and Bakker, A. B. (2018), "Daily spillovers from family to work: A test of the work-home resource model", Journal of Occupational Health Psychology, Vol. 23 No. 2, pp. 227-247. 
Ekman, S. (2015). Critical and Compassionate Interviewing: Asking Until it Makes Sense. In E. Jeanes and T. Huzzard (eds), Critical Management Research: Reflections From the Field (119-134). London: Sage.

Ekop, E. E. (2019), "Medical doctors and leadership positions in Abuja, Nigeria: A gender perspective", International Journal of Gender and Women's Studies, pp. 114-119.

Feeney, M. K. and Stritch, J. M. (2017), "Family-friendly policies, gender, and work-life balance in the public sector", Review of Public Personnel Administration, Sage Journal, pp. $1-27$.

Guest, G., Bunce, A. and Johnson, L. (2006), "How many interviews are enough? An experiment with data saturation and variability", Field Methods, Vol. 18 No. 1, pp. 59-82.

Herbst, L. Coetzee, S. and Visser, D. (2007), "Personality, sense of coherence and coping of working mothers", SA Journal of Industrial Psychology, Vol. 33 No. 3, pp. 57-67.

Hofstede, G. (1980). Culture's consequences: International differences in work-related values. Newbury Park, CA: Sage.

Lazarus, R. S. and Folkman, S. (1984) Stress, Appraisal and Coping, Springer, New York.

Lewis, S., Gambles, R. and Rapoport, R. (2007), “The constraints of a 'work-life balance' approach: an international perspective", The International Journal of Human Resource Management, Vol. 18 No. 3, pp. 306-373.

Lincoln, Y. and Guba, E. (1985), Naturalistic inquiry, Beverly Hills, CA: Sage.

Lister, R. (2003). Citizenship: Feminist perspective (2nd edn.). London: Palgrave.

Lupu, I., Spence, C. and Empson, L. (2018), "When the past comes back to haunt you: The enduring influence of upbringing on the work-family decisions of professional parents", Human Relations, Vol. 71 No. 2, pp. 155-181.

Makama, J. G., Garba, E. S. and Ameh, E. A. (2012), "Under Representation of Women in Surgery in Nigeria: By Choice or by Design?”, Oman Medical Journal, Vol. 27 No. 1, pp. 6669.

McDonald, P., Townsend, K. and Wharton, A. (2013), "The legitimation and reproduction of discourse-practice gaps in work-life balance”, Personnel Review, Vol. 42 No. 2, pp. 205-222.

Mordi, C., Mmieh, F. and Ojo, S. I. (2013), “An exploratory study of managers' perspective of worklife balance in Nigeria: A case analysis of the Nigerian banking sector", Thunderbird International Business Review, Vol. 55 No. 1, pp. 55-75.

Mushfiqur, R., Mordi, C., Oruh, E. S., Nwagbara, U., Mordi, T. and Turner, I. M. (2018). The impacts of work-life-balance (WLB) challenges on social sustainability: The experience of Nigerian female medical doctors. Employee Relations, 40(5), 868-888.

National Population Commission of Nigeria. (2017), State population, www.population.gov.ng/index.php/state-population. (Accessed on 09/10/2019). 
Özbilgin, M. F., T., Beauregard, T. A., Tatli, A. and Bell, M. P. (2010), "Work-Life, Diversity and Intersectionality: A Critical Review and Research Agenda", International Journal of Management Reviews, Blackwell Publishing, pp. 1-22.

Pedersen, V. B. and Lewis, S. (2012), "Flexible friends? Flexible working time arrangements, blurred work-life boundaries and friendship", Work, Employment and Society, Vol. 26 No. 3, pp. 464-480.

Porns, L. W., Fleming, L. C. and Jacobsen, K. H. (2016), "Work-family conflict, stress, and physical and mental health: A model for understanding barriers to and opportunities for women's well-being at home and in the workplace", World Medical \& Health Policy, Vol. 8 No. 4, pp. 444-457.

Pratt, M. G., Rockmann, K. W. and Kaufmann, J. B. (2006), "Professional identity: The role of work and identity learning cycles in the customization of identity among medical residents", The Academy of Management Journal, Vol. 49 No. 2, pp. 235-262.

Radenbach, C., Reiter, A. M. F., Engert, V., Sjoerds, Z., Villringer, A., Heinze, H., Desernoa, L. and Schlagenhauf, F. (2015), "The interaction of acute and chronic stress impairs modelbased behavioral control”, Psychoneuroendocrinology, Elsevier, Vol. 53, pp. 268-280.

Rajadhyaksha, U. (2012), "Work-life balance in South East Asia: the Indian experience", South Asian Journal of Global Business Research, Vol. 1 Issue: 1, pp.108-127.

Rotondo, D. M., Carlson, D. S. and Kincaid, J. F. (2003), "Coping with multiple dimensions of work-family conflict”, Personnel Review, Vol. 32 No. 3, pp. 275-296.

Saldaňa, J. (2012), The coding manual for qualitative researchers (2nd ed.). Thousand Oaks, CA: Sage.

Saunders, M., Lewis, P. and Thornhill, A. (2012), Research methods for business students (6th Ed.). London, England: Prentice Education Limited.

Shockley, K. M., Shen, W. and Johnson, R. C. (2018), The Cambridge handbook of the global work-family interface, New York, NY: Cambridge University Press.

Siegrist, J. (1996), "Adverse health effects of high-effort/low-reward conditions", Journal of Occupational Health Psychology, Vol. 1, pp. 27-41.

Sok, J., Blomme, R. and Tromp, D. (2014), "Positive and negative spillover from work to home: The role of organisational culture and supportive arrangement, British Journal of Management, Vol. 25, pp. 456-472.

Thakur, M., Bansal, A. Maini, R. (2018), "Job sharing as a tool for flexible work systems: Creating opportunities for housewives in the Indian labor market", Gender in Management: An International Journal, Vol. 33 Issue: 5, pp. 350-366.

Toffoletti, K. and Starr, K. (2016), "Women Academics and Work-Life Balance: Gendered Discourses of Work and Care", Gender, Work \& Organization, Vol. 23 No. 5, pp. 489-504.

Uziel, N., Meyerson, J., Birenzweig, Y. and Eli, I. (2018), "Professional burnout and work stress among Israeli dental assistants", Vol. 4, Psychology, Health \& Medicine, Taylor \& Francis, pp. 1-9. 
Visser, F. and Williams, L. (2006), "WLB, rhetoric versus reality? An independent report commissioned by UNISON. London: The Work Foundation.

Walsh, J. (2013), Gender, the Work-Life Interface and Wellbeing: A Study of Hospital Doctors", Gender, Work \& Organization, Vol. 20 No. 4, pp. 439-453.

Wilkinson, K., Tomlinson, J. and Gardiner, J. (2018), "The perceived fairness of work-life balance policies: A UK case study of solo-living managers and professionals without children”, Human Resource Management Journal, Vol. 18, No. 2, pp. 325-339.

Working Time Directive in Directive 2003/88/EC of the European Parliament and of the Council of 4 November 2003 concerning certain aspects of the organisation of working time, www.osha.europa.eu/en/legislation/directives/directive-2003-88-ec accessed on 16/11/2019. 